\title{
Exploring Factors Related to Completion of an Online Undergraduate-Level Introductory Statistics Course
}

\author{
Whitney Alicia Zimmerman and Glenn Johnson \\ The Pennsylvania State University
}

\begin{abstract}
Data were collected from 353 online undergraduate introductory statistics students at the beginning of a semester using the Goals and Outcomes Associated with Learning Statistics (GOALS) instrument and an abbreviated form of the Statistics Anxiety Rating Scale (STARS). Data included a survey of expected grade, expected time commitment, and the first lesson quiz. At the end of the semester, whether each student completed the course with a grade of D or higher was recorded. It was hypothesized that students who successfully completed the course would have favorable ratings on each of these variables. While there were no significant differences between students who did and did not successfully complete the course in terms of anxiety, attitudes, or expected time commitment, students who completed the course had higher scores on the GOALS, higher expected grades, and higher scores on the first quiz of the semester. Stepwise logistic regression found that students' attitudes towards statistics teachers and scores on the first quiz of the semester could be used to predict whether students would successfully complete the course. Based on these findings, suggestions for online instructors are given.
\end{abstract}

Keywords: Statistics education, online education; retention

Zimmerman, W.A. \& Johnson, G. (2017). Exploring factors related to completion of an online undergraduate-level introductory statistics course. Online Learning, 21(3), 191-205. doi: 10.24059/olj.v21i3.1017

\section{Introduction}

Attrition rates in online courses can vary greatly (Carr, 2000). For the online introductory statistics course examined in the present study, the course completion rate was around $70 \%$ in previous semesters. This means that approximately $30 \%$ of students enrolled in the course at the drop/add deadline, which is typically early in the second week of the semester, either dropped or withdrew from the course or finished the semester with a grade of F. In order to improve the completion rate in this course, an understanding of the variables, related or unrelated, to successful course completion is required. Of particular interest in this study were variables that may be influenced by an intervention provided within the course. The goal of this research was not merely to predict which students would not successfully complete the course, but rather to identify variables related to course completion that may be the target of future interventions.

In a recent special issue of Online Learning that focused on learning analytics, James, Swan, and Daston (2016) examined variables related to retention in students taking only face-toface courses, students taking only online courses, and students taking both face-to-face and online courses. While their primary purpose was to compare students in these three groups, they also provided data concerning retention rates for students enrolled in different types of institutions with 
different demographic characteristics. They found that for students enrolled in a primarily online university, those with a Pell grant were more likely to be retained than those without a Pell grant. They also found that females were more likely to be retained, as well as students over the age of 26. While these results concerning types of courses taken and demographics do provide information that can be used to predict whether a student will be successful, these variables cannot be controlled by an instructor. In the present study, variables that may be influenced by instructors will be examined.

Many students enter their required introductory statistics course with high levels of anxiety and relatively negative attitudes (DeVaney, 2010; Onwuegbuzie, 2004; Zeidner, 1991). Misconceptions that an introductory statistics course is a mathematics course may be partially responsible for this, resulting in mathematics anxiety (Pan \& Tang, 2005; Zeidner, 1991). In reality, the mathematical operations that students are required to perform in this course are limited, as online simulations and statistical software are often used. In interviews with students with high statistics anxiety, Malik (2015) found that this anxiety could lead students to feelings of defeat and poor performance in the course. This was often the case in the course featured in the present study; the majority of students who failed the course in the past did not submit numerous assignments. Instructors have also noted that some students have low grade expectations and are satisfied to earn the lowest grade necessary to fulfill their degree requirements (typically a $\mathrm{C}$ or $\mathrm{D}$ ). On a positive note, DeVaney did observe that online statistics students' anxiety levels decreased from the beginning to end of the course and that their attitudes become more positive. This shows that attitudes and anxieties about statistics are subject to change over the course of one semester.

Two research questions concerning successful course completion were addressed in the present study, where successful course completion was defined as finishing the course with a grade of $\mathrm{D}$ or higher. The two research questions were:

(1) Do students who successfully complete the course differ from those who do not successfully complete the course in terms of their attitudes, anxieties, expectations, and performance in the early weeks of the course?

(2) What variables can be used to best predict successful course completion?

It was hypothesized that students who did successfully complete the course had more positive attitudes, lower levels of anxiety, higher expectations, and better performance in the early weeks of the course compared to students who did not successfully complete the course. The purpose of constructing a model to predict successful course completion was to identify the variables that have the strongest relationship with course completion and that may be used to design an intervention to improve course completion rate.

\section{Literature Review}

The present study examined retention in an online undergraduate-level introductory statistics course. While the literature revealed no studies utilizing these specific parameters, studies examining retention in online courses were abundant, including many case studies that emphasized factors at the institutional level (e.g., Bloemer, 2009; Clark, Holstrom, \& Millacci, 2009; Fasse, Humbert, \& Rappold, 2009; Meyer, Bruwelheide, \& Poulin, 2009). The present study, however, emphasized factors at the student level. More specifically, the emphasis was on student-level factors that could be targeted for intervention and influenced by online statistics instructors. Only 
one study concerning retention in an online statistics course could be located. That study will be reviewed first. Then, studies concerning retention in online courses will be reviewed.

The one study that specifically addressed retention in an online statistics course compared face-to-face, hybrid, and online sections of an introductory statistics course at one community college. All three formats of the course used the same materials and were taught over four semesters. This study found no statistically significant differences among the three formats of the course in terms of mid-term exam scores $(p=.596)$, final exam scores $(p=.305)$, or average exam scores $(p=.246)$. Neither did the formats reveal proportional differences in terms of students who began the course who remained in the course to complete the mid-term exam $(p=.203)$ or finalexam $(p=.089)$. While course completion rates were slightly lower for the online sections of the course, online students who did complete the course actually had slightly higher exam scores and overall course grades compared to students in the face-to-face and hybrid sections, although none of these differences were statistically significant (Sami, 2011).

\section{Retention in Online Courses}

The results of numerous studies examining completion rates in online courses vary greatly. Some researchers have compared the completion rates of online courses to traditional face-to-face courses. For example, Atchley, Wingenbach, and Akers (2013) compared the course completion rates of 5,778 students enrolled in online and/or traditional face-to-face sections of the same courses with the same instructors. Their results were statistically significant $\left[\chi^{2}(1)=14.132, p<\right.$ $.001]$ with the online students having a $93.3 \%$ completion rate and the traditional students having a 95.6\% completion rate. They also compared completion rates by discipline and found a significant relationship between discipline and course completion $\left[\chi^{2}(13)=96.974, p<.001\right]$ although this study combined online and traditional courses, and statistics was not one of the disciplines examined.

The online course completion rate of 93.3\% provided by Atchley, et al. (2013) is higher than the completion rates provided by others. Carr (2000) reported that across 35 online courses at one large community college the completion rate was 58\%. Bälter, et al. (2013) examined an online mathematics course and an online programming course and found competition rates of $37 \%$ and $69 \%$ respectively. In the online course studied in the present research, the completion rate in recent semesters was around $70 \%$. For case studies concerning institutions with high completion rates, see the October 2009 (volume 13, issue 3) issue of the Journal of Asynchronous Learning Networks.

In terms of student variables related to successful course completion, Bälter, et al. (2013) examined students' approaches to learning in relation to their course completion. They found that in a programming course, students who successfully completed the course scored higher on subscales measuring deep approaches to learning, such as seeking meaning and relating ideas. Students who successfully completed a mathematics course also scored higher on subscales concerning deep approaches, specifically, relating ideas, and scored higher on subscales concerning strategic approaches to learning, specifically, time management and achievement. They did not find a significant difference between male and female students in terms of course completion nor did they find a major effect based on prior experience in higher education.

Aragon and Johnson (2008) also studied student variables related to the successful completion of online courses. Their students were enrolled in online courses at a rural community college. They did not find significant differences between online students who did and did not 
successfully complete their course in terms of age $[\mathrm{t}(303)=1.09, \mathrm{p}=.28]$, ethnicity $\left[\chi^{2}(1)=0.49\right.$, $\mathrm{p}=.48]$, financial aid eligibility $\left[\chi^{2}(1)=0.03, \mathrm{p}=.87\right]$, placement in developmental courses [reading: $\chi^{2}(1)=0.05, \mathrm{p}=.83$; writing: $\chi^{2}(1)=2.84, \mathrm{p}=.09$; or mathematics: $\chi^{2}(1)=1.29, \mathrm{p}=$ $.26]$, or scores on a measure of self-directed learning readiness $[\mathrm{t}(303)=-0.58, \mathrm{p}=.56]$. They did find a significant difference for gender $\left[\chi^{2}(1)=5.64, p=.02\right]$ with a $66 \%$ completion rate for women and a $52 \%$ completion rate for men. On average, students who successfully completed courses were enrolled in more credits during that semester $[\mathrm{t}(303)=9.33, \mathrm{p}<.001]$ and had higher overall grade point averages $[\mathrm{t}(303)=4.45, \mathrm{p}<.001]$. A sample of students who did not successfully complete a course was surveyed and five themes were identified: personal reasons and time constraints, course design and communication, technology, institutional issues, and learning preferences.

\section{Factors Related to Student Success in Statistics}

In the present study, variables that could be impacted by interventions in an introductory statistics course were selected to be studied. Because instructors have no influence over gender, financial aid eligibility, family responsibilities, or employment status, these variables were excluded. Instead, emphasis focused on students' perceptions and behaviors. These included anxiety levels and attitudes concerning statistics, which have been studied in the field of statistics education but not in relation to attrition in online courses. Expected grade was included in this study because instructors have noted students' satisfaction with a C or D in the course. Intended time commitment was included because students have commented on mid-semester feedback surveys in previous semesters that the course was more time consuming than others. Finally, performance on the first quiz of the course was included as a measure of students' activity early in the semester. A pre-test of demonstrated knowledge was included to assess preexisting knowledge level differences among students who ultimately did and did not successfully complete the course.

\section{Participants}

\section{Methods}

In the fall 2015 semester 564 students were enrolled across 14 sections of an undergraduate-level introductory statistics course through one large, multi-campus university's online campus. The instructors of 12 sections agreed to have their students participate in the study. Instructors were not given any information concerning the purpose of the study. Data related to general research concerning course completion and student learning in relation to national norms were routinely collected from students. It was not unusual for instructors to ask their students to take surveys in this course. Of the 484 students enrolled in those 12 sections, 385 students completed the survey during the first week of class and 353 gave permission for their data to be used in research.

The demographic characteristics of the students who agreed to participate in this research study were not available. However, students who enrolled in this course were representative of the population of undergraduate students enrolled through the University's online campus. The average age of an undergraduate student is 31 years. In terms of sex, 52.7\% of students are female and $47.3 \%$ are male. This course is a general education course and it required for many majors. Thus, the students enrolled in the course represent a wide variety of majors including business, communications, nursing, and criminal justice. 


\section{Procedures}

During the first week of the course students were asked to complete the Goals and Outcomes Associated with Learning Statistics (GOALS) instrument and an abbreviated form of the Statistics Anxiety Rating Scale (STARS). In addition to these two scales, which will be described in greater detail below, students were asked to identify their final grade and time commitment expectations. Students' grades on the first quiz of the course were also recorded. Final course grades were used to determine whether students successfully completed the course. A grade of D or higher was necessary to be classified as having successfully completed the course. Students who finished the course with a final grade of $\mathrm{F}$ and students who dropped or withdrew were classified as not having successfully completed the course.

\section{Instrumentation}

Goals and Outcomes Associated with Learning Statistics (GOALS). The GOALS was used as a measure of demonstrated knowledge of introductory statistics concepts. The GOALS was completed online and consists of 20 multiple-choice items that test concepts commonly covered in introductory statistics courses such as variability, sampling variation, confidence intervals, and p-values. Each of the 20 questions is worth 5 points, with a possible range of scores from 0 to 100 . The instrument was developed primarily at the University of Minnesota's Department of Educational Psychology as part of the Assessment Resource Tools for Improving Statistical Thinking (ARTIST) and eATLAS NSF-funded projects (Lock Morgan, 2015). Measures of internal consistency (e.g., Cronbach's alpha) could not be computed because individual student responses were not available; only composite scores were available. While no published manuscripts concerning the psychometric properties of the GOALS were reviewed, this is an assessment that aligns with the curriculum of the course in the present study.

Statistics Anxiety Rating Scale (STARS). An abbreviated form of the STARS was developed for this study. The original version of the STARS was created by Cruise, Cash, and Bolton (1985). Hanna, Shevlin, and Dempster's (2008) revision of the STARS was used as the starting point for the development of the abbreviated scale. Both Cruise et al.'s and Hanna et al.'s versions consisted of 51 items on six subscales: test anxiety, asking for help anxiety, interpretation anxiety, attitudes towards statistics teachers, self-concept, and worth of statistics. A shorter form was needed for this study due to time constraints; this was a part of a larger survey being taken by students in the course who were also completing other assessments during the same time period.

The six subscale model validated by Hanna, et al. (2008) served as the basis for the abbreviated form. Three items were selected on each of the six subscales resulting in a total of 18 items. These items were selected on the basis of Hanna et al.'s standardized factor loadings and on the basis of what was most logical, given that students in the present study were all enrolled in an online course. Items on the anxiety subscales (test, asking for help, and interpretation) were measured using a five-point anxiety scale ranging from "no anxiety" to "very strong anxiety." Items on the attitudes subscales (teachers, self-concept, and worth) were measured using a standard five-point Likert scale from "strongly disagree" to "strongly agree."

Because this abbreviated form of the STARS had not previously been used, it was necessary to evaluate its psychometric properties. Confirmatory factor analysis was used to examine the use of the six-factor structure as opposed to a more parsimonious two- or one-factor structure. The one-factor model included all 18 items on one factor. For the two-factor model, items on the anxiety subscales were combined to create the first factor and items on the attitudes 
subscales were combined to create the second factor. The six-factor model used the original six subscale structure from Cruise et al. (1985) and Hanna et al. (2008). The three models were estimated using IBM SPSS Amos 23.0.0. Maximum likelihood estimations were used for all models. In the two- and six-factor models, all latent factors were allowed to correlate. No correlated errors were included in any of the models. The results of these analyses are presented in Table 1. All fit indices suggested that the most appropriate model for these data is the six-factor model.

\begin{tabular}{ccccccc}
\hline Model & $D f$ & $\chi^{2}$ & $\begin{array}{c}\text { RMSEA } \\
{[90 \% \mathrm{CI}]}\end{array}$ & CFI & $\begin{array}{c}\text { ECVI } \\
{[90 \% \mathrm{CI}]}\end{array}$ & MECVI \\
\hline One-Factor & 135 & $1697.388^{*}$ & $\begin{array}{c}.181 \\
{[.174, .189]}\end{array}$ & 0.567 & $\begin{array}{c}5.129 \\
{[4.762,5.517]}\end{array}$ & 5.146 \\
& & & & & \\
Two-Factor & 135 & $1075.866^{*}$ & $\begin{array}{c}.141 \\
{[.134, .149]}\end{array}$ & 0.749 & $\begin{array}{c}3.369 \\
{[3.083,3.676]}\end{array}$ & 3.387 \\
& & & & & 1.004 & \\
Six-Factor & 120 & $211.383^{*}$ & {$[.037, .058]$} & 0.974 & {$[0.898,1.132]$} & 1.026 \\
\hline$* p<0.001$ & & & & & &
\end{tabular}

$* p<0.001$
Note: $\mathrm{RMSEA}=$ root mean square error of approximation; $\mathrm{CI}=$ confidence interval; $\mathrm{CFI}=$ comparative fit index; ECVI = expected cross-validation index; MECVI = modified expected cross-validation index; Sample size for all analyses was 353.

Table 1. Confirmatory Factor Analysis Results

\section{Descriptive Statistics}

\section{Results}

Of the 353 students who agreed to participate in the study, $254(72.0 \%)$ successfully completed the course. Of the remaining 99 students, 38 (10.8\%) stayed enrolled through the end of the semester but received a grade of F, and $61(17.3 \%)$ students dropped or withdrew from the class before the end of the semester.

Descriptive statistics concerning all participants' responses to each of the STARS items are presented in Table 2. Higher scores on the anxiety subscales represent higher levels of anxiety. High scores on the attitudes subscales represent stronger agreement with the statement and thus, more negative attitudes. 


\begin{tabular}{|c|c|c|c|c|}
\hline Scale & Item Stem & $\mathrm{N}$ & Mean & SD \\
\hline Test Anxiety & $\begin{array}{l}\text { Studying for an examination in a statistics } \\
\text { course }\end{array}$ & 349 & 3.21 & 1.087 \\
\hline Test Anxiety & $\begin{array}{l}\text { Doing an examination in a statistics } \\
\text { course }\end{array}$ & 350 & 3.42 & 1.179 \\
\hline Test Anxiety & $\begin{array}{l}\text { Waking up in the morning on the day of a } \\
\text { statistics test }\end{array}$ & 349 & 2.91 & 1.271 \\
\hline Asking Anxiety & $\begin{array}{l}\text { Contacting my statistics instructor for } \\
\text { help with material I am having } \\
\text { difficulty understanding }\end{array}$ & 347 & 2.04 & 1.046 \\
\hline Asking Anxiety & $\begin{array}{l}\text { Asking one of my instructors for help in } \\
\text { understanding a printout }\end{array}$ & 347 & 1.93 & 1.022 \\
\hline Asking Anxiety & $\begin{array}{l}\text { Asking a fellow student for help in } \\
\text { understanding a printout }\end{array}$ & 350 & 2.00 & 1.037 \\
\hline $\begin{array}{c}\text { Interpretation } \\
\text { Anxiety }\end{array}$ & $\begin{array}{l}\text { Making an objective decision based on } \\
\text { empirical data }\end{array}$ & 350 & 2.26 & 0.992 \\
\hline $\begin{array}{c}\text { Interpretation } \\
\text { Anxiety }\end{array}$ & $\begin{array}{l}\text { Reading a journal article that includes } \\
\text { some statistical analyses }\end{array}$ & 351 & 1.81 & 0.865 \\
\hline $\begin{array}{l}\text { Interpretation } \\
\text { Anxiety }\end{array}$ & $\begin{array}{l}\text { Trying to understand the statistical } \\
\text { analyses described in the abstract of a } \\
\text { journal article }\end{array}$ & 348 & 2.55 & 1.030 \\
\hline Worth of Statistics & I feel statistics is a waste & 349 & 1.82 & 0.809 \\
\hline Worth of Statistics & $\begin{array}{l}\text { I wish the statistics requirement would be } \\
\text { removed from my academic major }\end{array}$ & 350 & 2.56 & 1.269 \\
\hline Worth of Statistics & I am never going to use statistics & 350 & 1.88 & 0.907 \\
\hline $\begin{array}{l}\text { Attitudes Towards } \\
\text { Statistics Teachers }\end{array}$ & $\begin{array}{l}\text { Statistics teachers are so abstract they } \\
\text { seem inhuman }\end{array}$ & 345 & 1.89 & 0.829 \\
\hline $\begin{array}{l}\text { Attitudes Towards } \\
\text { Statistics Teachers }\end{array}$ & $\begin{array}{l}\text { Statistics teachers communicate in a } \\
\text { different language }\end{array}$ & 351 & 2.32 & 0.972 \\
\hline $\begin{array}{l}\text { Attitudes Towards } \\
\text { Statistics Teachers }\end{array}$ & $\begin{array}{l}\text { Statisticians are more number oriented } \\
\text { than they are people oriented }\end{array}$ & 350 & 2.63 & 1.018 \\
\hline Self-Concept & $\begin{array}{l}\text { I cannot even understand high school } \\
\text { math; I don't see how I can possibly } \\
\text { do statistics }\end{array}$ & 352 & 2.07 & 1.151 \\
\hline Self-Concept & $\begin{array}{l}\text { Since I never enjoyed math, I do not see } \\
\text { how I can enjoy statistics }\end{array}$ & 351 & 2.24 & 1.214 \\
\hline Self-Concept & $\begin{array}{l}\text { I do not have enough brains to get through } \\
\text { statistics }\end{array}$ & 351 & 1.95 & 1.057 \\
\hline
\end{tabular}

Table 2. Descriptive Statistics for STARS Items 
Descriptive statistics for the six STARS subscales scores from all participants are presented in Table 3. Subscale scores were computed by adding each participant's response to the three items on each scale. If one or more items on a subscale were not answered, that individual's subscale score was not computed. With each item rated on a scale of 1 to 5 , subscale scores could range from 3 to 15 . Cronbach's alpha was used as a measure of internal consistency for each subscale. All alpha coefficients were judged to be sufficient, given that each subscale had only three items. The correlations between the six STARS subscales scores are presented in Table 4.

\begin{tabular}{lcccc} 
& N & Mean & SD & $\begin{array}{c}\text { Cronbach's } \\
\text { Alpha }\end{array}$ \\
Test Anxiety & 347 & 9.54 & 3.110 & .852 \\
Asking Anxiety & 343 & 5.97 & 2.828 & .899 \\
Interpretation Anxiety & 347 & 6.63 & 2.468 & .815 \\
Worth of Statistics & 346 & 6.26 & 2.563 & .791 \\
Attitudes Toward Statistics Teachers & 343 & 6.81 & 2.299 & .745 \\
Self-Concept & 350 & 6.27 & 3.102 & .888 \\
\hline
\end{tabular}

Table 3. Descriptive Statistics for Abbreviated STARS Subscales

\begin{tabular}{lllll}
1 & 2 & 3 & 4 & 5 \\
\hline
\end{tabular}

1. Test Anxiety

\begin{tabular}{lllllll}
\hline 2. Asking Anxiety & $\mathrm{r}$ & .441 & & & & \\
& $\mathrm{n}$ & 341 & & & & \\
\hline 3. Interpretation Anxiety & $\mathrm{r}$ & .680 & .470 & & & \\
& $\mathrm{n}$ & 343 & 339 & & & \\
\hline 4. Worth of Statistics & $\mathrm{r}$ & .366 & .287 & .419 & & \\
& $\mathrm{n}$ & 341 & 337 & 341 & & \\
\hline 5. Attitudes Towards Statistics & $\mathrm{r}$ & .274 & .176 & .243 & .567 & \\
Teachers & $\mathrm{n}$ & 338 & 335 & 338 & 338 & \\
\hline 6. Self-Concept & $\mathrm{r}$ & .491 & .289 & .531 & .647 & .498 \\
& $\mathrm{n}$ & 345 & 341 & 345 & 345 & 342 \\
\hline
\end{tabular}

All $\mathrm{p} \leq .001$

Table 4. Correlations between Abbreviated STARS Subscales

Scores on the GOALS assessment at the beginning of the semester were approximately normally distributed with a mean of 33.508 and standard deviation of $11.455(n=315)$. Only individuals' total scores were available to be analyzed. The variable concerning anticipated hours per week devoted to the course was slightly positively skewed with outliers; the median was 10 hours and the mean was 10.110 hours with a standard deviation of 5.030 hours $(n=350)$. The 
variable concerning expected final grade in the course was measured on an ordinal level scale and was highly negatively skewed; the median expected grade was $\mathrm{B}+$ and the mode was $\mathrm{A}$. Scores on the first quiz were negatively skewed with a mean of 77.106 and standard deviation of 21.111; the median was 83.926. Of the 344 participants enrolled in the course through the end of the second week of class when this quiz was completed, 17 (4.9\%) did not complete the quiz and received a grade of 0 .

\section{Research Question 1}

The first research question was "Do students who successfully complete the course differ from those who do not successfully complete the course in terms of their attitudes, anxieties, expectations, and performance in the early weeks of the course?" Because the STARS subscales were moderately correlated with one another, a multivariate analysis of variance (MANOVA) was used to compare the students who did and did not successfully complete the course. The remaining variables were analyzed separately. Note that with the exception of within the MANOVA, no corrections were made for multiple tests. Thus, the results of the statistical analyses may be liberal.

STARS subscale scores were compared for participants who did and did not successfully complete the course using a MANOVA. The overall test was not statistically significant [Wilks' Lambda $=.922, \mathrm{~F}(6,316)=0.624, \mathrm{p}=.711$, partial eta squared $=.012$ ]. There were also no significant differences between the participants who did and did not successfully complete the course on any of the six STARS subscales. While students who did successfully complete the course had lower scores on every subscale, signifying lower anxiety and more positive attitudes, the differences were all small (Cohen's d ranging from 0.115 to 0.194).

The scores of students who completed the GOALS in the first week of class were compared for students who did and did not successfully complete the course. The results were statistically significant $[\mathrm{t}(313)=1.660, \mathrm{p}=.049]$. However, the effect size of this difference was small among participants who did successfully complete the course, scoring 0.213 standard deviations higher than the participants who did not successfully complete the course.

The expected grades of participants who did and did not successfully complete the course were compared using a Mann-Whitney $U$ test. This test was statistically significant $[z=2.097, p$ $=.018]$. Students who successfully completed the course had higher expected grades. For those who did successfully complete the course the median expected grade was A- and the mode was A. For those who did not successfully complete the course the median expected grade was $\mathrm{B}+$ and the modes were B and A-.

For both groups, expected hours per week devoted to the course were slightly positively skewed with outliers. A Mann-Whitney U test was used to compare the students who did and did not successfully complete the course on this variable. The results of this test were not statistically significant $[\mathrm{z}=0.343, \mathrm{p}=.366]$. The median for participants who did successfully complete the course was 10 hours per week and the median for participants who did not successfully complete the course was 9.50 hours per week.

Finally, scores on the first quiz of the course were compared for the two groups. Scores for both groups were negatively skewed with outliers who did not complete the quiz and therefore scored a 0. A Mann-Whitney $U$ test was also used for this analysis. There was a statistically significant difference $(\mathrm{z}=4.351, \mathrm{p}<.001)$. The median score for participants who did successfully 
complete the course was $85.714(\mathrm{~N}=254)$ and the median score for participants who did not successfully complete the course was $78.571(\mathrm{~N}=90)$.

To summarize the results concerning the first research question, there were no significant differences between participants who did and did not successfully complete the course in terms of any of the six STARS subscales. Participants who did complete the course had scored better on the GOALS, however the difference was small. The expected grades of participants who completed the course were higher than those of participants who did not successfully complete the course. There was not a difference between the two groups of participants in terms of the hours per week they expected to devote to the course. The largest effect size between the two groups of students related to their performance on the first quiz of the course. Students who successfully completed the course had higher scores on the first quiz.

\section{Research Question 2}

The second research question was, "What variables can be used to best predict successful course completion?" To examine how the available variables could be used to predict successful course completion, backward stepwise (Wald) logistic regression methods were used. This allowed for the specification of a simple model that could be used to predict a student's probability of successful course completion.

The initial model contained the six STARS subscales, GOALS score, expected grade, expected hours per week devoted to the course, and grade on the first quiz. The final model consisted of the attitudes towards statistics teachers, subscale of the STARS, scores on the first quiz of the course, and a constant. This model was statistically significant $\left[\chi^{2}(2)=22.267, p<\right.$ $.0001]$. Prediction success overall was $76.5 \%$ (97.6\% for those who did successfully complete the course, $11.6 \%$ for those who did not successfully complete the course).

To summarize the results concerning the second research question, a model for predicting successful course completion was constructed using logistic regression. While the resulting model was statistically significant, the sensitivity of the test was less than desirable. In other words, the model was only able to correctly identify $11.6 \%$ of the students who would not successfully complete the course. Its level of specificity, however, was very good in that the model was able to correctly identify $97.6 \%$ of students who would successfully complete the course.

\section{Limitations}

A number of limitations were identified during data collection and analysis. First, of the 484 students enrolled in the sections of the course involved in the study, only 353 students (72.9\%) completed the survey and gave permission for their data to be used for research purposes. There was a relationship between giving permission to participate in the study and course completion $\left[\chi^{2}\right.$ $(1)=25.150, p<.001$, Cramer's $V=.228$ ]. Of the students who gave permission, $72.2 \%$ completed the course while only $47.7 \%$ of students who did not give permission, either because they did not submit the survey or because they stated that they did not want to be included in the study, completed the course. Thus, the results may be influenced by the available data. Again, this suggests that active engagement in the early weeks of the course is an important predictor of successful completion of the course.

Second, the GOALS score, which was used as a measure of knowledge during the first and last weeks of the course, has not been validated for use as a pre-test. This is a limitation of the 
study because the validity and reliability of scores from this assessment is unknown. Only students' composite scores on this assessment were available for analysis and, thus, it was not possible to compute any measures of internal consistency such as Cronbach's alpha. In the future, a measure of knowledge that has been specifically validated for use as a pre-test should be selected.

\section{Discussion}

The results provided evidence that students who successfully completed the online undergraduate-level introductory statistics course in this study had higher GOALS scores, higher expected grades, and higher scores on the first quiz of the semester compared to the students who did not successfully complete the course. Here, the implications of these results are discussed. Suggestions for future research, including interventions to improve successful course completion, are discussed.

Students who successfully completed the course had lower levels of anxiety and more positive attitudes at the beginning of the course compared to students who did not successfully complete the course. However, the differences between students who did and did not successfully complete the course were relatively small and not statistically significant. Future research should examine anxiety and attitudes on a more task-specific level. This might be achieved, for example, by focusing at the question-level as opposed to the scale-level. In this study students gave the highest anxiety ratings to the question "Doing an examination in a statistics course." Anecdotally, students also experienced anxiety while taking the course's weekly quizzes. This anxiety may prevent some students from taking the quizzes which, in turn, decreases their likelihood of successfully completing the course. An intervention targeting anxiety during quizzes and exams may emphasize test-taking strategies and general anxiety reduction.

Students who successfully completed the course had, on average, higher scores on the GOALS assessment. This, along with the variability of the GOALS scores, suggests that some students entered the course with some pre-existing content knowledge and that those students are more likely to be successful than students who entered the course with less content knowledge. While instructors have no control over their students' prior coursework, they could provide students with materials to review before the course begins. For example, students may be given the option of reading review materials or working through Khan Academy (https://www.khanacademy.org/) lessons designed for high school students that cover some of the course topics at a more introductory level, such as basic measures of central tendency (i.e., mean, median, and mode) or interpreting graphs (e.g., bar charts and scatterplots). Instructors should reach out to students who score poorly on the measure of demonstrated knowledge during the first week of the course in order to reassure students that they are not expected to score highly on an assessment of information that they have not yet been taught. This should help to ensure that the experience of struggling through such an assessment did not have a negative impact on students' confidence. To further offset these issues, GOALS will be replaced by a different measure of demonstrated knowledge in the future. Currently, the use of open-ended prompts that ask students to interpret situations similar to those addressed in the course are being explored (Zimmerman, et al., 2016).

The median expected grade was higher for the students who successfully completed the course. There are a number of reasons why a student could have a low-grade expectation at the beginning of the semester. For example, they may begin the course with the belief that they do not 
have the ability to do well. This is sometimes attributed to students' beliefs about their mathematics abilities (Azar \& Mahmoudi, 2014) which may be addressed by showing students that the introductory statistics course is not a mathematics course. The mathematical operations required in the course are limited to addition, subtraction, multiplication, division, square roots, exponents, and possibly factorials. Students may also begin the course with low grade expectations because they anticipate putting forth only enough effort to obtain the minimum required grade. The minimal grade that students must achieve in order for the course to be counted toward their graduation requirements varies by major but is typically a $\mathrm{C}$ or $\mathrm{D}$. If a student's major requires a $\mathrm{C}$ in the course in order for it to count toward graduate requirements, then the student may be aiming for a $\mathrm{C}$. The issue with this is that the course material is somewhat cumulative and becomes more difficult as the semester progresses. A student aiming for a $\mathrm{C}$ during the first half of the semester may find it difficult to maintain that $C$ through the end of the semester when the content becomes more challenging. As a result, instructors should reach out to students who begin the course with low grade expectations to determine if they are experiencing low self-efficacy or if their strategy is to do the minimal amount of work to pass the course. The appropriate intervention varies by the cause of the low-grade expectation. For instance, for students planning to do the minimal amount of work, instructors may point out that exam grades tend to decline from the first to the second midterm and again to the final exam. They may also share anecdotal evidence from previous semesters. Instructors should remind students that those who fall behind for more than one or two weeks rarely catch up. On the other hand, students with low self-efficacy may benefit from activities that build their confidence. For example, easy early activities that gradually become more difficult may prevent students from giving up. In this course, students also stated that attending group review sessions with peer leaders was helpful, both to recognize that other students share their feelings and to work through content at an appropriate pace.

Students who do poorly on the first quiz of the semester or who do not complete the first quiz of the semester are at high risk for not completing the course. Of the students who completed the first quiz of the semester, $75.8 \%$ successfully completed the course while only $35.3 \%$ of students who did not complete the first quiz successfully completed the course. Students who do not complete the first quiz are less than half as likely to successfully complete the course compared to students who do complete the first quiz. Instructors should reach out to students who do not complete the first quiz to determine why they did not complete it and develop an intervention to target each individual's issues since such students are beginning the course with a low grade and are missing out on this learning opportunity. While it is possible for students to avoid the first quiz and catch up, we see that the majority of students who miss the first quiz never do so and fail to successfully complete the course.

In terms of predicting which students will and will not successfully complete the course using data collected in the first two weeks of the semester, students' attitudes toward statistics teachers and scores on the first quiz were identified as statistically significant predictors. While the sensitivity of that model to identify students who would not successfully complete the course was poor, the specificity of the model was good. In other words, students who successfully completed the course were correctly classified, but students who did not successfully complete the course were not consistently correctly classified. It may be better to be optimistic and to predict that a student will successfully complete the course when he or she will not than to be pessimistic and to predict that a student will not successfully complete the course when they may. If instructors know that a student is not likely to be successful they may interact with the student differently (Rosenthal \& Jacobson, 1966). Thus, it is preferable to overestimate success in the course. When 
reaching out to a poorly performing student, an instructor should do so with the perspective that the student can be successful as to not further discourage the student.

The STARS subscale of attitudes towards statistics teachers was a statistically significant predictor of course completion, although the MANOVA, comparing students who did and did not successfully complete the course in terms of their STARS subscales scores did not identify a statistically significant difference in terms of this variable. The mean ratings of participants who did complete the course were 0.194 standard deviations lower than the mean ratings of participants who did not successfully complete the course. Note that the attitudes items were all worded in a way that higher ratings are associated with more negative perceptions. Thus, students who successfully completed the course had less negative (i.e., more positive) views of statistics teachers. This study used an abbreviated form of the STARS wherein the attitudes towards statistics teachers subscale consisted of the following three statements to which students rated their level of agreement on a scale of 1 to $5(1=$ strongly disagree, $5=$ strongly agree): "Statistics teachers are so abstract they seem inhuman," "Statistics teachers communicate in a different language," and "Statisticians are more number oriented than they are people oriented." For the first statement, students who completed the course gave a mean rating of $1.84(\mathrm{SD}=0.806, \mathrm{~N}=$ $250)$ while students who did not complete course gave a mean rating of $2.01(\mathrm{SD}=0.881, \mathrm{~N}=95)$ for a difference of 0.206 standard deviations. For the second statement, students who did not complete the course gave a mean rating of $2.28(\mathrm{SD}=0.962, \mathrm{~N}=253)$ while students who did not complete the course gave a mean rating of $2.43(\mathrm{SD}=0.995, \mathrm{~N}=98)$ for a difference of 0.154 standard deviations. For the third statement, students who completed the course gave a mean rating of $2.58(\mathrm{SD}=1.004, \mathrm{~N}=252)$ while students who did not complete the course gave a mean rating of $2.73(\mathrm{SD}=1.051, \mathrm{~N}=98)$ for a difference of 0.147 standard deviations. For all three items, students who successfully completed the course gave more positive ratings. The effect sizes were consistent across all three items and were relatively small in each case. Based on students' perceptions of statistics teachers, several suggestions for instructors emerge. The use of individual emails and instructional videos for the class may help to "humanize" the instructor. Instructors of introductory courses should also consider their language choices with students and avoid excessive jargon that may reinforce perceptions of statistics as a special and inaccessible language, or statisticians as number oriented. Instructors of introductory courses who can communicate the content in a language that novice learners can most easily comprehend may be most effective in improving their students' perceptions of individuals in the field of statistics.

\section{Conclusions}

The results of this study suggest that indicators, as early as the first week of the course, may be used to identify students who are at-risk for not successfully completing the course. The purpose of this study, however, was not to simply identify the students who are likely to fail to be successful in the course but rather to identify variables that provide meaningful opportunity for interventions. A number of interventions were suggested, including those with the goals of reducing test anxiety, increasing existing content knowledge at the beginning of the course, and improving students' perceptions statistics teachers. Future research should develop interventions that can be used in online introductory statistics courses targeting one or more of these areas and report on their effectiveness at improving course completion rates as well as other outcomes such as exam performance and student satisfaction. 


\section{References}

Aragon, S. R., \& Johnson, E. S. (2008). Factors influencing completion and noncompletion of community college online courses. The American Journal of Distance Education, 22, 146158.

Atchley, T. W., Wingenbach, G., \& Akers, C. (2013). Comparison of course completion and student performance through online and traditional courses. International Review of Research in Open and Distance Learning, 14(4), 104-116.

Azar, F. S., \& Mahmoudi, L. (2014). Relationship between mathematics, self-efficacy, and students' performance in statistics: The mediation role of attitude toward mathematics and mathematics anxiety. Journal of Educational Science \& Psychology, IV(LXVI), 32-42.

Bälter, O., Cleaveland-Innes, M., Pettersson, K., Scheja, M., \& Svedin, M. (2013). Student approaches to learning in relation to online course completion. Canadian Journal of Higher Education, 43(3), 1-18.

Bloemer, B. (2009). The UIS model for online success. Journal of Asynchronous Learning Networks, 13(3), 99-115.

Carr, S. (2000). As distance education comes of age, the challenge is keeping the students. The Chronicle of Higher Education, 46(23), A39-41.

Clark, M., Holstrom, L., \& Millacci, A. M. (2009). University of Cincinnati: Case study of online student success. Journal of Asynchronous Learning Networks, 13(3), 99-115.

Cruise, R. H., Cash, R. W., \& Bolton, D. L. (1985). Development and validation of an instrument to measure statistical anxiety. ASA Proceedings of the Statistical Education Section, American Statistical Association. Alexandria, VA. 92-97.

DeVaney, T. A. (2010). Anxiety and attitudes of graduate students in on-campus vs. online statistics courses. Journal of Statistics Education, 18(1).

Fasse, R., Humbert, J., \& Rappold, R. (2009). Rochester Institute of Technology: Analyzing student success. Journal of Asynchronous Learning Networks, 13(3), 99-115.

Hanna, D., Shevlin, M., \& Dempster, M. (2008). The structure of the Statistics Anxiety Rating Scale: A confirmatory factor analysis using UK psychology students. Personality and Individual Differences, 45(1), 68-74.

James, S., Swan, K., \& Daston, C. (2016). Retention, profession and the taking of online courses. Online Learning, 20(2).

Lock Morgan, K. (2015). Statistics Department 2015 Assessment. Unpublished internal report. 
Meyer, K. A., Bruwelheide, J., \& Poulin, R. (2009). Why they stayed: Near-perfect retention in an online certification program in library media. Journal of Asynchronous Learning Networks, 13(3), 99-115.

Onwuegbuzie, A. (2004). Academic procrastination and statistics anxiety. Assessment and Evaluation in Higher Education, 29, 3-19.

Pan, W., \& Tang, M. (2005). Students' perceptions of factors of statistics anxiety and instructional strategies. Journal of Instructional Psychology, 32(3).

Rosenthal, R., \& Jacobson, L. (1966). Teachers' expectancies: Determinants of pupils’ IQ gains. Psychological Report, 19(1), 115-188.

Sami, F. (2011). Course format effects on learning outcomes in an introductory statistics course. MathAMATYC Educator, 2(2), 48-51. Retrieved from www.amatyc.org/resource/resmgr/educator_feb_2011/sami-courseformat-feb11.pdf

Zeidner, M. (1991). Statistics and mathematics anxiety in social science students: Some interesting parallels. British Journal of Educational Psychology, 61, 319-328.

Zimmerman, W. A., Kang, H. B., Kim, K., Johnson, G., Clariana, R., \& Zhang, F. (October 26, 2016). Computer-based approach for measuring changes in introductory statistics students' knowledge structures. Paper presented at the Annual Meeting of the Northeastern Educational Research Association, Trumbull, CT. 